\title{
Late Quaternary Environmental and Human Impacts on the Mitochondrial DNA Diversity of Four Commensal Rodents in Myanmar
}

\author{
San Maung Maung Theint ${ }^{1} \cdot$ Thidalay Thwe $^{1} \cdot$ Khin Myat Myat Zaw $^{1} \cdot$ Tomofumi Shimada $^{2} \cdot$ Saw Bawm $^{3}$. \\ Motoko Kobayashi $^{4} \cdot$ Khin Maung Saing $^{1} \cdot$ Ken Katakura $^{5} \cdot$ Satoru Arai ${ }^{6} \cdot$ Hitoshi Suzuki $^{4}$ (i)
}

Accepted: 8 September 2020 / Published online: 24 September 2020

(C) The Author(s) 2020

\begin{abstract}
We addressed the spatiotemporal characteristics of four commensal rodent species occurring in Myanmar in comparison with other areas of the Indo-Malayan region. We examined sequence variations of the mitochondrial cytochrome $b$ gene $(C y t b)$ in the Pacific rat (Rattus exulans), roof rat (Rattus rattus complex, $\mathrm{RrC}$ ), lesser bandicoot rat (Bandicota bengalensis), and house mouse (Mus musculus) using the recently developed time-dependent evolutionary rates of mtDNA. The Cytb sequences of RrC from Myanmar were shown to belong to RrC Lineage II, and their level of genetic diversity was relatively high compared to those of the other three species. $\mathrm{RrC}$ was found to have experienced bottleneck and rapid expansion events at least twice in the late Pleistocene period in Myanmar and a nearby region. Accordingly, paleoclimatic environmental fluctuations were shown to be an important factor affecting rodents in the subtropics of the Indo-Malayan region. Our results show that human activities during the last 10,000 years of the Holocene period affected the population dynamics of the rodent species examined, including introducing them to Myanmar from neighboring countries. Further study of these four commensal rodents in other geographic areas of the Indo-Malayan region would allow us to better understand the factors that drove their evolution and their ecological trends.
\end{abstract}

Keywords Commensal rodents · Genetic diversity $\cdot$ Population dynamics $\cdot$ Quaternary environmental fluctuations $\cdot$ Myanmar

Electronic supplementary material The online version of this article (https://doi.org/10.1007/s10914-020-09519-4) contains supplementary material, which is available to authorized users.

Hitoshi Suzuki

htsuzuki@ees.hokudai.ac.jp

1 Department of Zoology, University of Yangon, Yangon 11041, Myanmar

2 International Language \& Business Centre, Yangon 11211, Myanmar

3 Department of Pharmacology and Parasitology, University of Veterinary Science, Yezin, Nay Pyi Taw 15013, Myanmar

4 Graduate School of Environmental Earth Science, Hokkaido University, North 10, West 5, Sapporo 060-0810, Japan

5 Graduate School of Infectious Diseases, Faculty of Veterinary Medicine, Hokkaido University, North 18, West 9,

Sapporo 060-0818, Japan

6 Infectious Disease Surveillance Center, National Institute of Infectious Diseases, Tokyo 162-8640, Japan

\section{Introduction}

The subfamily Murinae is a large taxonomic group that consists of more than 500 species found mainly in the IndoMalayan region, a region of southern Asia with a high level of terrestrial animal biodiversity (Musser and Carleton 2005; Srinivasulu and Srinivasulu 2012) covering South and Southeast Asia and southern China. Some murine rodents, such as rats and mice, that live within or close to human habitations are called commensal rodents and have affected human activities in a variety of ways, such as by causing agricultural damage (Aplin et al. 2003) and carrying infectious diseases (Kosoy et al. 2015). On the other hand, such species can provide useful information for clarifying human movements from prehistoric to modern times (Boursot et al. 1993; Matisoo-Smith and Robins 2004; Aplin et al. 2011; Jones et al. 2013; Thomson et al. 2014). Phylogeographic analyses have been conducted for a number of species of commensal rodents, and anthropological factors were found to have shaped the genetic structures of commensal rodent species over the last 15,000 years (Auffray and Britton-Davidian 
2012; Aplin et al. 2011; Conroy et al. 2013; Suzuki et al. 2013). The impacts of both humans and the natural environment were likely involved in the processes that shaped their genetic variation. However, the evolutionary histories of many of these species have not yet been fully elucidated.

Myanmar is located in the central part of the Indo-Malayan region and plays a role connecting neighboring countries including India, China, Thailand, and Indonesia. In addition, Myanmar harbors its own species and lineages, and it is essential to understand the functions of physical barriers such as mountain ranges in the emergence of genetic variation within these lineages. In the Indo-Malayan region, the Arakan Mountain system on the border of India and Myanmar may act as a geographic barrier, dividing the region into two parts (Chingangbam et al. 2015). Mountain ranges have been shown to act as borders between species or local intraspecies phylogroups in species of the genus Mus (Shimada et al. 2007, 2009, 2010; Myat Myat Zaw et al. 2019). Widespread taxonomic groups are ideal systems for testing biogeographical hypotheses, as they provide an opportunity for examining how geographical barriers, as well as the processes of dispersal and colonization, affect diversification and determine biogeographical distribution patterns (e.g., Irschick et al. 1997). In Myanmar, commensal murine rodents are abundant and represented by the Pacific rat (Rattus exulans), roof rat (Rattus rattus complex, $\mathrm{RrC}$ ), lesser bandicoot rat (Bandicota bengalensis), and house mouse (Mus musculus). Due to their large impacts on human welfare (Thomson et al. 2018), it is necessary to elucidate the genetic structure and inferred demographics of commensal rodents in Myanmar.

Rattus exulans is a common commensal rodent variably described as a 'ground rat' (Medway 1969) and 'highly arboreal' (Aplin et al. 2003). It is distributed in Southeast Asia, the Indonesian islands, and the Pacific Islands. According to Corbet and Hill (1992), it is a common pest species found in houses, granaries, cultivated areas, scrubland, and forests, usually on the ground. In Thailand, it has been reported in houses, markets, the vicinity of houses, and in rice paddies located near buildings (Marshall 1988). Rattus exulans has also attracted the attention of researchers interested in anthropogenic movements across the deep sea via ships in the Pacific Islands (Matisoo-Smith and Robins 2004), with this species acting as a symbiotic animal by providing nutrition to humans. Human-mediated dispersal of these rats among the Pacific Islands is an issue of great concern. Based on a mitochondrial DNA (mtDNA) phylogeographic survey of $R$. exulans diversity across its potential natural range of mainland (MSEA) and island (ISEA) areas of Southeast Asia, prehistoric MSEA and ISEA rodent fauna have been confirmed (Thomson et al. 2014). The highest mtDNA lineage diversities, including significant haplotype diversity, were observed in ISEA populations of $R$. exulans. From the results of that study and other evidence, Flores Island, Indonesia, is predicted to be the origin of this species (Thomson et al. 2014). The survey of MSEA remains limited to date, and it is necessary to address this issue through the collection of more specimens from MSEA.

The roof rat (or ship rat) exhibits strong arboreal features and is predicted to have its origins in Asia; thus, it is common in the Indo-Malayan region today. The species is known to include complicated geographic groups and was recently recognized as the $\mathrm{RrC}$, containing six distinct mitochondrial cytochrome $b(C y t b)$ sequences (Lineage I-VI) with apparent geographic affinity (Chinen et al. 2005; Pagès et al. 2010; Tollenaere et al. 2010; Aplin et al. 2011). Eastern and Southern India, representing $\mathrm{RrC}$ Lineage $\mathrm{I}$, is the likely geographical focus of the $2 n=38$ karyotype group, whereas the geographic area covering the easternmost part of India to southern China represents the natural range of $\mathrm{RrC}$ Lineage II, representing chromosome form $2 \mathrm{n}=42$, also called $R$. tanezumi. Although this mtDNA lineage extends to the easternmost part of Eurasia-the Japanese Islands (Chinen et al. 2005; Kambe et al. 2012), the place of origin of this species and evolutionary events of range expansion of $\mathrm{RrC}$ II have not yet been determined. Although phylogenetic and phylogeographic studies have been carried out for RrC (Pagès et al. 2010, 2013; Aplin et al. 2011), intensive genetic analysis of populations in Myanmar has not yet been reported.

The bandicoot rats (genus Bandicota) are pest rodent species that are abundant and widespread throughout the continental portion of the Indo-Malayan region. Recently, a molecular phylogenetic study was conducted on the three bandicoot rat species from Myanmar, where all three species of this genus, $B$. bengalensis, $B$. indica, and $B$. savilei, occur and a number of genetic sequences of $B$. bengalensis from Myanmar have been published (Mori et al. 2020). While B. bengalensis inhabits a wide area of Myanmar and is relatively dense in population, the recovered $C y t b$ sequences were shown to contain limited nucleotide diversity and to exhibit a localityspecific pattern; i.e., each locality tends to possess a single haplotype (Mori et al. 2020). However, no detailed temporal mechanism has been inferred to assess the evolutionary history of this species.

The evolutionary history of $M$. musculus has been extensively studied. Three major subspecies groups, including M. musculus castaneus (CAS), are known to have extended their ranges alongside prehistoric human movements during the development of agriculture across the Eurasian Continent (e.g., Boursot et al. 1993). The South Asian group M. m. castaneus is known to contain four distinct mtDNA 
sublineages, referred to here as CAS 1-4 (Suzuki et al. 2013). One of these lineages, CAS-1, is now present over a wide area of India, Southeast Asia, East Asia, and the associated islands of Japan, Philippines, and Indonesia after an episodic expansion event ca. 7000-8000 years ago (Suzuki et al. 2013; Kuwayama et al. 2017). The CAS-1 sublineage experienced a secondary expansion event in southern China that extended its range to Japan and southern Sakhalin (Suzuki et al. 2013). In a previous study, the extent of genetic diversity in $C y t b$ sequences was found to be relatively small in Myanmar (Suzuki et al. 2013; Myat Myat Zaw et al. 2019), indicating that recent structuring of the population had occurred due to the introduction of human agricultural systems in Southeast Asia including Myanmar. However, details of the evolutionary progress of M. musculus in Myanmar are not yet known.

The influence of Quaternary environmental changes accompanying glacial-interglacial cycles and sea-level fluctuations (Lambeck et al. 2002; Lisiecki and Raymo 2005; Bintanja et al. 2005; Jansen et al., 2017), including major impacts shaping the genetic diversity of terrestrial animals, have been well documented. In particular, the last (LGM, ca. 20,000 years ago) and penultimate (PGM, ca. 140,000 years ago) glacial maxima are reported to have had strong effects on the present genetic structures of species with temperate origins. Population expansion events have been deduced for rodents dwelling in temperate forests (genus Apodemus) (Hanazaki et al. 2017). In addition, population expansion events have been inferred for subarctic grassland-dwelling rodents (genus Myodes) (Kohli et al. 2015; Honda et al. 2019) during the intermediate period $50,000-60,000$ years ago, when warmer conditions were beginning during early marine oxygen isotope stage 3 (MIS 3) after a substantially colder period (MIS 4) (e.g., Sawagaki et al. 2004; Shang et al. 2018). Therefore, we sought to determine whether these critical periods of drastic environmental change during the late Quaternary affected the population dynamics of species in subtropical areas.

In this study, we addressed the evolutionary history of four commensal rodents that are common in Myanmar based on variations in their mtDNA sequences. We collected $R$. exulans, $\mathrm{RrC}$, and M. musculus from Myanmar and analyzed their Cytb nucleotide sequences. We also obtained Cytb sequences for $R$. exulans (Thomson et al. 2014), M. musculus (e.g., Myat Myat Zaw et al. 2019), and B. bengalensis (Mori et al. 2020) and sequences for $\mathrm{RrC}$ and M. musculus from Manipur, a state in northeastern India (Chingangbam et al. 2015) from databases. In addition, $C y t b$ sequences from other geographic regions were obtained from databases for phylogeographic assessment. The study of these four commensal rodent species allows us to compare their histories and discuss their commonalities and differences. This in turn may provide useful clues to better understand the factors driving genetic variation and to elucidate the zoogeographic role of Myanmar, the center of the Indo-Malayan region.

\section{Materials and Methods}

\section{Sample Collection}

Sample collection in Myanmar was conducted mainly by staff members of the Department of Zoology, University of Yangon from 2013 to 2018. For this study, 35 individuals of Rattus exulans, 13 individuals of $\mathrm{RrC}$, and 4 individuals of M. musculus were collected and subjected to molecular analysis (Table 1, Fig. 1).

\section{Sequencing Analysis}

DNA was extracted from the liver tissue from each individual using a Qiagen DNA Isolation kit (Hilden, Germany) following the manufacturer's protocol. Sequence determination was performed for Cytb (1034-1140 bp) in accordance with a method described previously (Suzuki et al. 2015). The gene region was amplified through polymerase chain reaction (PCR) using the following protocol: $95^{\circ} \mathrm{C}$ for $10 \mathrm{~min}$, followed by 30 cycles of $95^{\circ} \mathrm{C}$ for $30 \mathrm{~s}, 50^{\circ} \mathrm{C}$ for $30 \mathrm{~s}$, and $60^{\circ} \mathrm{C}$ for $60 \mathrm{~s}$, and finally, $72^{\circ} \mathrm{C}$ for $7 \mathrm{~min}$. PCR products were sequenced using a PRISM Ready Reaction Dye DeoxyTerminator Cycle Sequencing kit Ver 3.1 and an ABI 3500 Genetic Analyzer (Applied Biosystems, Foster City, CA, USA). The nucleotide sequences reported in the present study appear in the DDBJ, EMBL, and GenBank nucleotide sequence databases under accession numbers LC510767LC510818.

\section{Phylogenetic Analysis}

Long (1034 bp) and short (381 bp) Cytb sequences of $R$. exulans were obtained from databases and used for phylogenetic inference based on datasets of the MSEA and MSEA plus ISEA haplotypes. Database sequences of $\operatorname{RrC}$ (1140 bp, $1034 \mathrm{bp}$ ) were used in this study. We obtained 24 Cytb sequences of B. bengalensis (1026 bp, $1140 \mathrm{bp}$ ) from the databases, 23 of which were collected from Myanmar (MK654761-MK654784) and one from Pakistan (AM408336). Cytb sequences of M. musculus from Myanmar were obtained from databases (LC426295-LC426303). Phylogenetic trees were constructed based on the maximum likelihood (ML) method using MEGA ver. 7.0 software (Kumar et al. 2016) with the substitution models GTR $+\mathrm{G}$ $(R$. exulans $), \mathrm{TN} 93+\mathrm{G}+\mathrm{I}(\mathrm{RrC}), \mathrm{TN} 93+\mathrm{G}$ (B. bengalensis), and TN93 (M. musculus). The best fit model was determined using the Akaike information 
Table 1 List of Myanmar samples subjected to sequence analysis in this study

\begin{tabular}{|c|c|c|c|c|c|}
\hline \multirow{2}{*}{$\frac{\text { Species }}{\text { Rattus exulans }}$} & \multicolumn{3}{|c|}{ Collection locality* } & \multirow{2}{*}{$\frac{\mathrm{n}}{1}$} & \multirow{2}{*}{$\begin{array}{l}\text { Sample code }{ }^{* *} \\
\text { MM3295 }\end{array}$} \\
\hline & 1. Kalaymyo & $23^{\circ} 11^{\prime} \mathrm{N}$ & $94^{\circ} 3^{\prime} \mathrm{E}$ & & \\
\hline & 2. Taunggyi & $20^{\circ} 47^{\prime} \mathrm{N}$ & $96^{\circ} 58^{\prime} \mathrm{E}$ & 1 & HS5251 \\
\hline & 3. Nay Pyi Taw & $19^{\circ} 50^{\prime} \mathrm{N}$ & $96^{\circ} 16^{\prime} \mathrm{E}$ & 2 & HS5236, HS5237 \\
\hline & & $19^{\circ} 50^{\prime} \mathrm{N}$ & $96^{\circ} 16^{\prime} \mathrm{E}$ & 3 & MM4414, MM4415, MM4420 \\
\hline & & $19^{\circ} 50^{\prime} \mathrm{N}$ & $96^{\circ} 16^{\prime} \mathrm{E}$ & 3 & MM4421, MM4422, MM4423 \\
\hline & 4. Pyay & $18^{\circ} 47^{\prime} \mathrm{N}$ & $95^{\circ} 14^{\prime} \mathrm{E}$ & 1 & YUZ40 \\
\hline & 6. Pathein & $16^{\circ} 56^{\prime} \mathrm{N}$ & $94^{\circ} 35^{\prime} \mathrm{E}$ & 9 & YUZ 1-3, YUZ5, YUZ12-15, YUZ17 \\
\hline & & $16^{\circ} 55^{\prime} \mathrm{N}$ & $94^{\circ} 39^{\prime} \mathrm{E}$ & 7 & YUZ 6-11, YUZ16 \\
\hline & & $16^{\circ} 54^{\prime} \mathrm{N}$ & $94^{\circ} 39^{\prime} \mathrm{E}$ & 6 & YUZ124-128, YUZ131 \\
\hline & & $16^{\circ} 47^{\prime} \mathrm{N}$ & $94^{\circ} 45^{\prime} \mathrm{E}$ & 1 & YUZ114 \\
\hline & & $16^{\circ} 39^{\prime} \mathrm{N}$ & $94^{\circ} 52^{\prime} \mathrm{E}$ & 1 & YUZ144 \\
\hline \multirow[t]{8}{*}{ Rattus rattus Complex (RrC) } & 1. Kalaymyo & $23^{\circ} 11^{\prime} \mathrm{N}$ & $94^{\circ} 3^{\prime} \mathrm{E}$ & 3 & MM3290, MM3291, MM3292 \\
\hline & 3. Nay Pyi Taw & $19^{\circ} 50^{\prime} \mathrm{N}$ & $96^{\circ} 16^{\prime} \mathrm{E}$ & 1 & HS5235 \\
\hline & & $19^{\circ} 41^{\prime} \mathrm{N}$ & $96^{\circ} 07^{\prime} \mathrm{E}$ & 2 & MM3166, MM3167 \\
\hline & & $19^{\circ} 48^{\prime} \mathrm{N}$ & $96^{\circ} 11^{\prime} \mathrm{E}$ & 1 & MM3179 \\
\hline & 4. Pyay & $18^{\circ} 47^{\prime} \mathrm{N}$ & $95^{\circ} 12^{\prime} \mathrm{E}$ & 2 & YUZ30/MM3833, YUZ42/MM3835 \\
\hline & 5. Yangon & - & - & 1 & NSMT-M43013 \\
\hline & & $16^{\circ} 50^{\prime} \mathrm{N}$ & $96^{\circ} 08^{\prime} \mathrm{E}$ & 1 & HS5399 \\
\hline & 6. Pathein & $16^{\circ} 56^{\prime} \mathrm{N}$ & $94^{\circ} 35^{\prime} \mathrm{E}$ & 2 & YUZ4, YUZ23/MM3830 \\
\hline Mus musculus & 2. Taunggyi & $20^{\circ} 35^{\prime} \mathrm{N}$ & $96^{\circ} 52^{\prime} \mathrm{E}$ & 4 & HS5243, HS5244, HS5247, HS5248 \\
\hline
\end{tabular}

*The collection points from Myanmar are indicated in Fig. 1b

**YUZ, University of Yangon, Zoology Department; HS, personal code of HS; MM, code of NIID (National Institute of Infectious Diseases, Japan); NSMT, National Science Museum Tokyo

criterion (AIC; Posada and Buckley 2004), as implemented in MEGA. Levels of genetic variation and divergence were assessed based on nucleotide diversity $(\pi)$ using ARLEQUIN ver. 3.5 software (Excoffier and Lischer 2010).

\section{Population genetic analysis}

Colonization (founder effect) and post-glacial environmental impacts were assessed by detecting the rapid expansion signal (Excoffier and Schneider 1999). Networks were constructed using the Median-Joining (MJ) method (Bandelt et al. 1999), as implemented in PopART software (Leigh and Bryant 2015). Mismatch distribution analysis and the neutrality tests Tajima's $D$ and Fu's $F_{\mathrm{S}}$ were performed using ARLEQUIN (Excoffier and Lischer 2010). The expected distribution was simulated for the sudden expansion model through mismatch distribution analysis, in which the validity of the model was tested using a parametric bootstrap approach with 1000 replicates. In this method, the sum of squared deviation (SSD) between the observed distribution and the expected distribution was compared with the SSD between the simulated distribution and expected distribution for each replicate. The raggedness index ( $r$; Harpending 1994) was used as a test statistic for the predicted sudden expansion model.

The expansion parameter tau $(\tau)$ was estimated for the $C y t b$ datasets using ARLEQUIN (Excoffier and Lischer 2010) in clusters that showed signs of sudden demographic expansion. The $95 \%$ confidence interval (CI) around the estimated $\tau$ parameter was determined using the bootstrap approach. The time since expansion in generation $(t)$ can be estimated by the formula $t=\tau$ / $2 u k$, where $u$ is the evolutionary rate per generation and $k$ is sequence length (Rogers and Harpending 1992; Rogers 1995). Here, the time since expansion in years (T) was estimated by the formula $T=\tau / 2 \mu \mathrm{k}$, where $\mu$ is the evolutionary rate per year, since $u=\mu \mathrm{g}$, and $t=T / g$, where $g$ is generation time in years. Here, we used evolutionary rates $\left(\mu^{\prime}\right)$ per million years (myr), for convenience.

In this study, we examined the evolutionary rate of the mitochondrial gene sequence change in a timedependent manner (Ho et al. 2011). Previously, we addressed rapid expansion events seen in local populations of wood mice and voles occurring in the Japanese archipelago and applied biogeographic events as 
Fig. 1 a Distribution ranges of Rattus exulans (Wilson et al. 2016), mtDNA lineage II of the R. rattus complex (RrC II; Aplin et al. 2011), Bandicota

bengalensis (Wilson et al. 2016), and mtDNA lineage CAS- 1 of

Mus musculus (Suzuki et al. 2013; Myat Myat Zaw et al. 2019). b Map of Myanmar showing the locations of study sites sampled in this investigation. The central dry zone is denoted by the dashed line. The thick dotted line indicates the approximate location of the Arakan Mountains

a

Rattus exulans

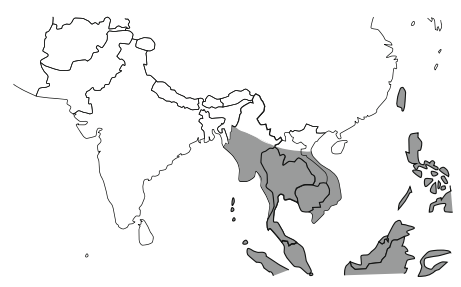

Bandicota bengalensis

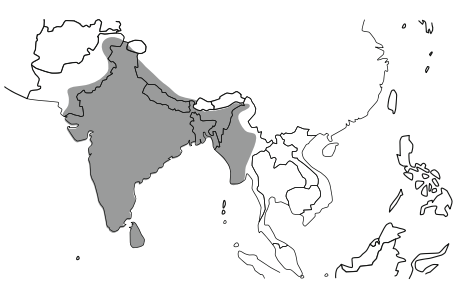

\section{R. rattus complex: Lineage II}

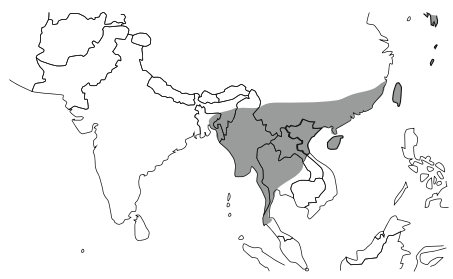

Mus musculus: CAS-1

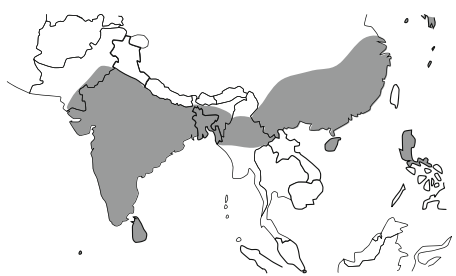

b

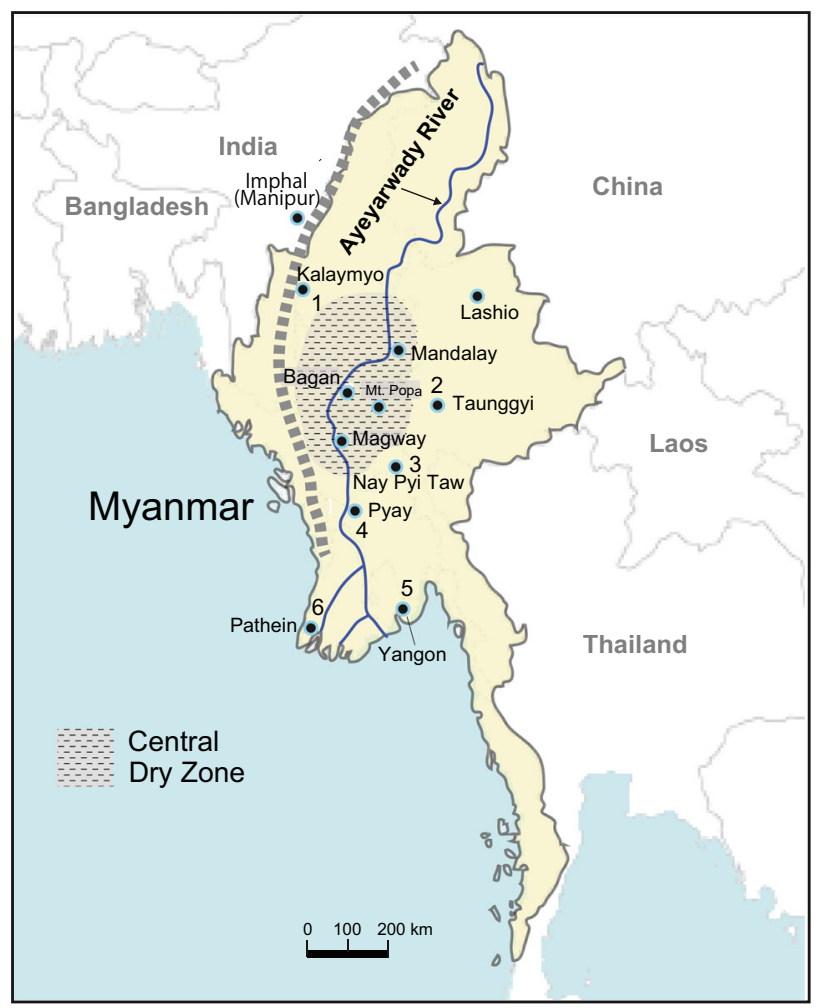

calibration points (Suzuki et al. 2015; Hanazaki et al. 2017; Honda et al. 2019). There are three classes of the $\tau$ values in the Cytb sequence (1140 bp) analysis, small $(\tau=2-4)$, intermediate $(\tau=5-6)$, and large $(\tau=7-9)$, which are considered to correspond to the historical events of the three rapid warming periods of the post
LGM, early MIS 3, and post PGM. Accordingly, we chose the evolutionary rate $(\mu$ ') as one of the options based on the obtained $0.11,0.047$, or 0.028 substitutions/site/myr, respectively (Honda et al. 2019).

Data for this study are available in the Dryad Digital Repository: https://doi.org/10.5061/dryad.7pvmcvdqm. 
a

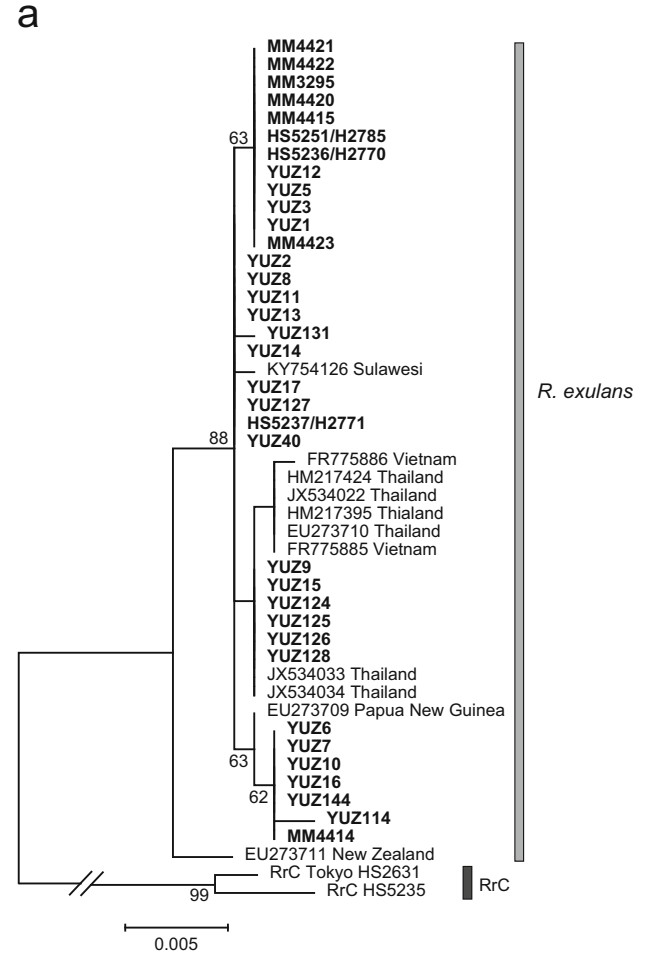

b

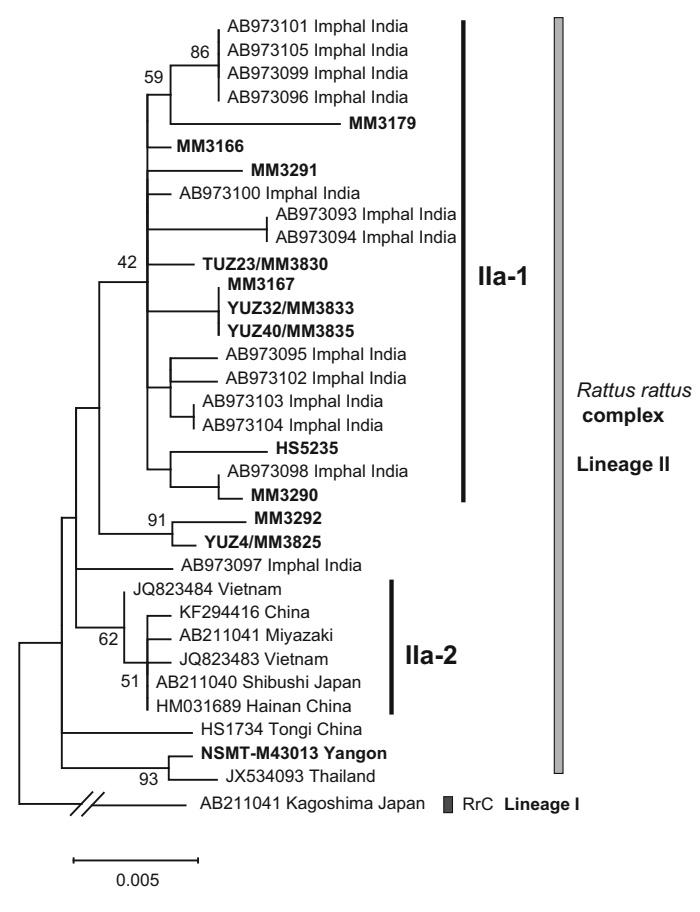

C

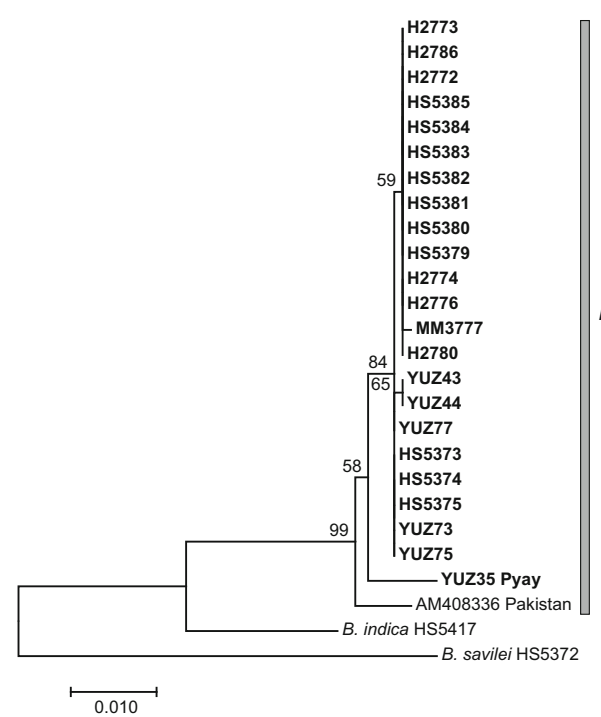

Fig. 2 Maximum likelihood relationships for a Rattus exulans, b RrC, c Bandicota bengalensis, and d Mus musculus based on Cytb sequences (1034-1140 bp). Cytochrome $b(C y t b)$ sequences of $\mathrm{RrC}$ and

\section{Results}

\section{Rattus exulans}

For $R$. exulans, we compared the $C y t b$ sequences (1034 bp) of 35 rats from Myanmar and 11 rats from other d

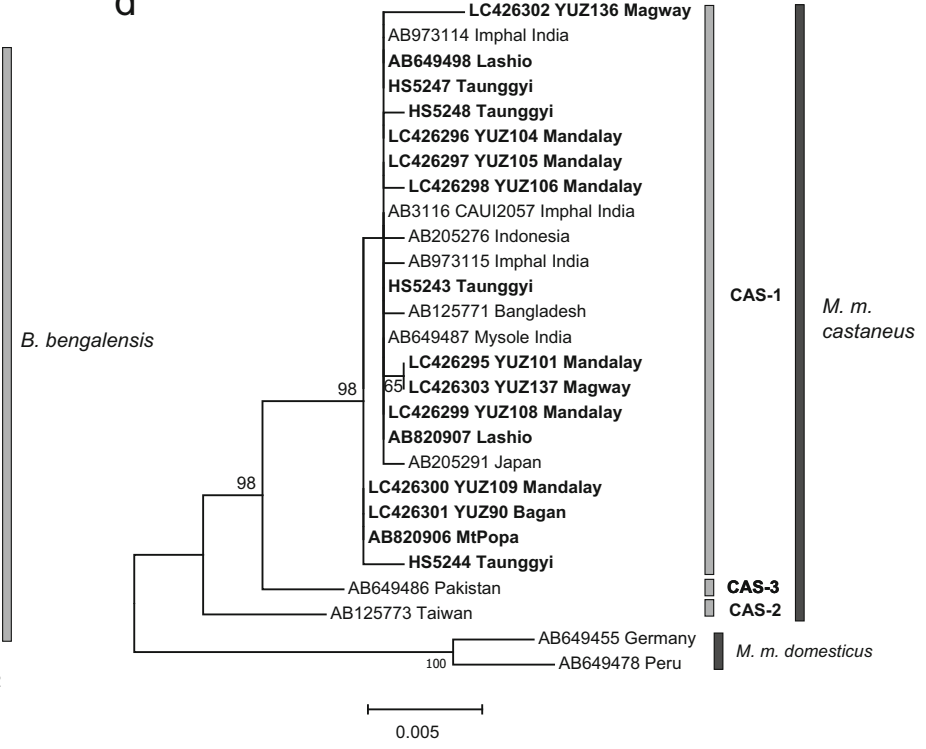

M. musculus from Manipur, India (Chingangbam et al. 2015) were used in this study. Values at nodes correspond to bootstrap values $>50 \%$. Each scale bar represents 0.005 sequence divergence

countries. A close relationship between haplotypes from Myanmar and those from other countries was observed in the ML tree (Fig. 2a) and in the MJ network (Fig. 3a), consistent with the low level of nucleotide diversity $(\pi=$ 0.0018; Table 2). Although the pattern obtained for the MJ network exhibited a broken star-like structure, the 
Fig. 3 Median joining networks of $C y t b$ sequences for a Rattus exulans (1034 bp and 381 bp), b $\mathrm{RrC}, \mathrm{c}$ Bandicota bengalensis, and d Mus musculus. Haplotype circles on networks are color coded according to geographic location. The size of the circle corresponds to the haplotype frequency. Slashes across branches represent numbers of mutational steps. Small black nodes represent extinct or unsampled haplotypes a

Rattus exulans

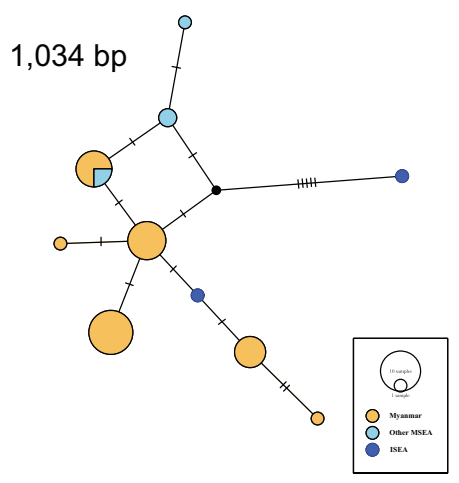

$381 \mathrm{bp}$

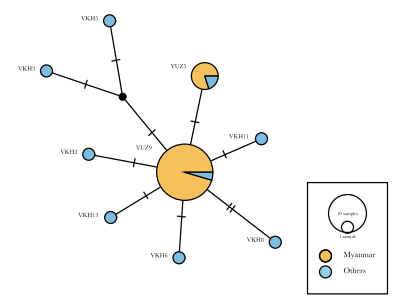

C Bandicota bengalensis

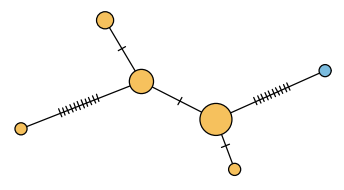

b Rattus rattus complex

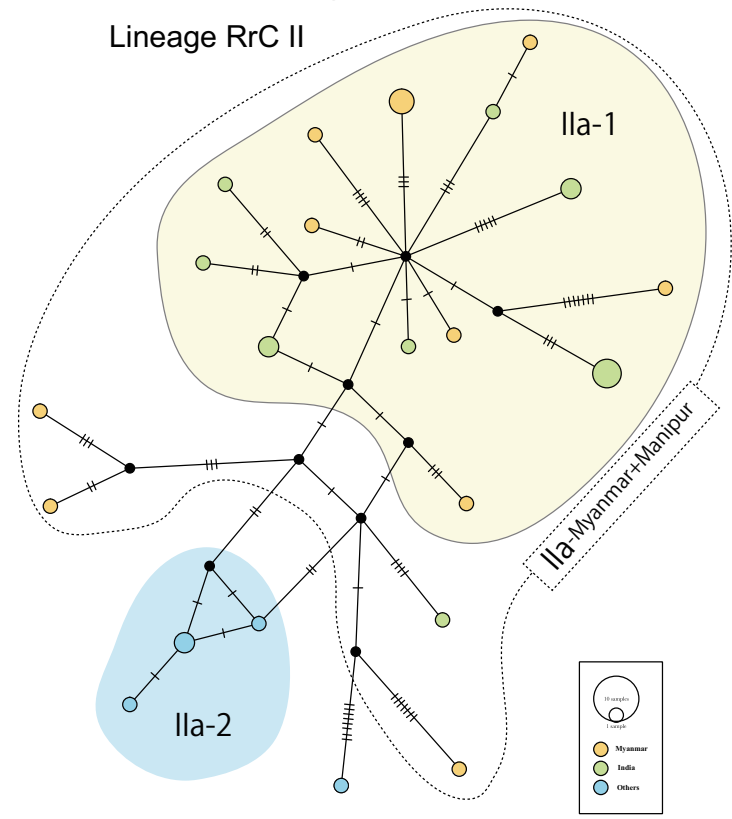

d Mus musculus

Lineage CAS-1
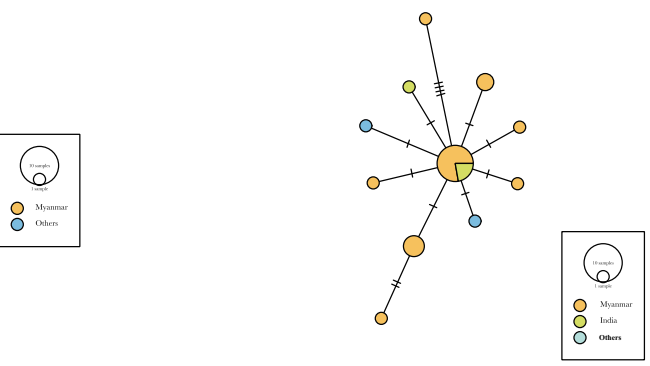

mismatch distribution analysis (Supplementary Fig. S1) and neutrality tests did not support the rapid expansion model (Table 2).

Phylogeographic analysis employed a 381-bp Cytb sequence dataset using database sequences (e.g., Thomson et al. 2014) covering haplotypes from ISEA $(n=10)$ and MSEA $(n=24)$. A star-like network was obtained, similar to that reported previously in a study of the mtDNA control region (Fig. 3a; Thomson et al. 2014). The neutrality tests provided evidence of rapid expansion. The mismatch distribution analysis resulted in a $\tau$ value of 0.94 (CI: 0.07-1.97) (Table 2). The time of expansion initiation was estimated as 11,200 years ago (CI: 840023,500 years ago) using an evolutionary rate of 0.11 substitutions/site/myr.

\section{RrC}

We collected 13 rats from Kalaymyo, Nay Pyi Taw, Pyay, Yangon, and Pathein along the Ayeyarwady River and found that all rats from Myanmar had pure white hairs on the ventral side. Analysis of the Cytb sequences (1140 bp) yielded eight haplotypes in total. ML tree construction of these and available database sequences (1034 bp) revealed that the haplotypes from Myanmar all belonged to RrC Lineage II (Fig. 2b), one of the six major mtDNA lineages of RrC defined by Aplin et al. (2011). This lineage is sometimes called ' $R$. tanezumi' and represents rats from East Asia, including the Japanese Islands (Fig. 1b).

We constructed an MJ network using Cytb sequences (1140 bp) from Myanmar and other countries $(n=30$; Fig. 3b). Network construction revealed a cluster with a star-like 


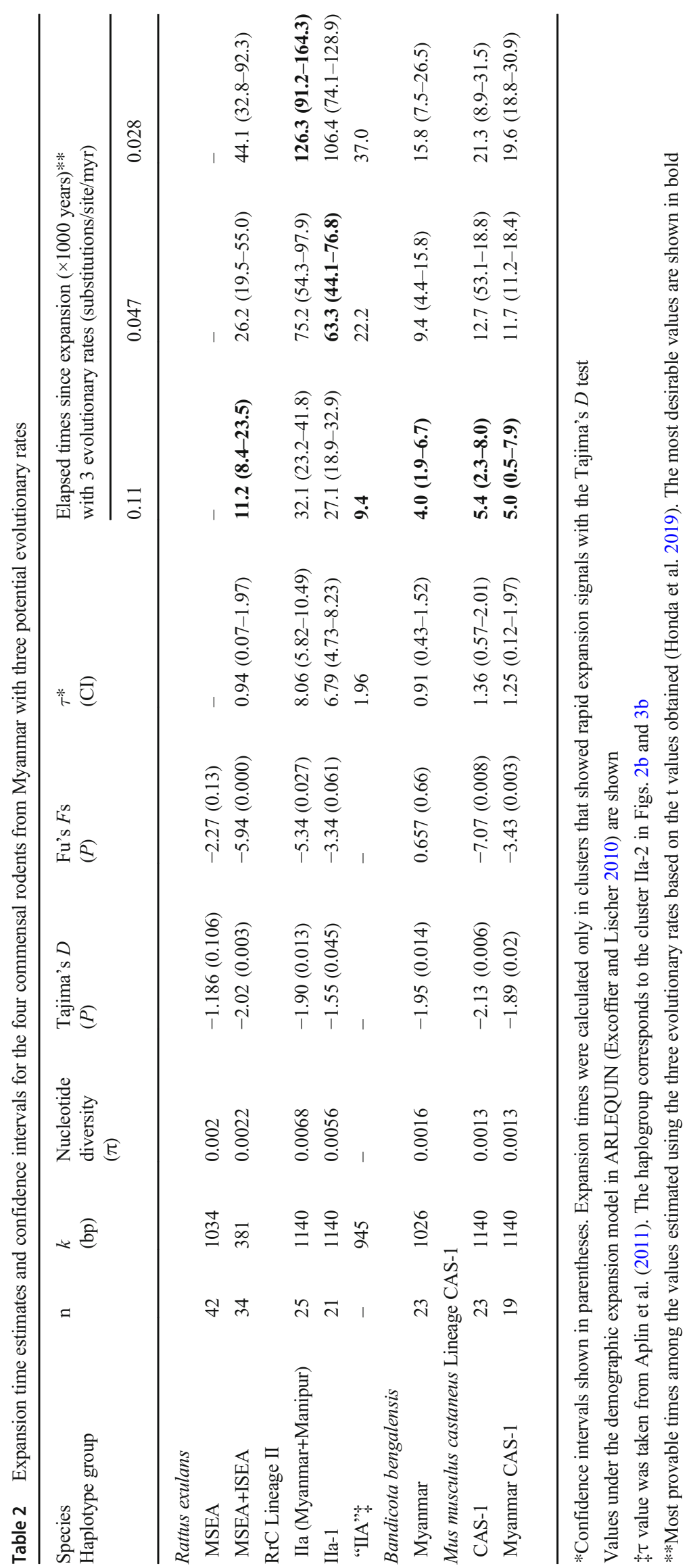


pattern comprising a subset of the haplotypes from Myanmar, which we denoted RrC IIa-1. Mismatch distribution analyses were carried out on the haplotype sets RrC Lineage IIa-1 ( $n=$ $21)$, and on all haplotypes $(n=25)$ from Myanmar and Manipur (Imphal, India), and each set exhibited significant signals of rapid expansion (Supplementary Fig. S1, Table 2). The $\tau$ value of the dataset of IIa-1 was 6.79 (CI: 4.73-8.23), with an estimated expansion-initiation time of 63,300 (CI: 44,100-76,800) years ago. The $\tau$ value obtained for the Myanmar (+Manipur) sequences was substantially larger, $\tau=8.06$ (CI: 5.82-10.49), with an estimated time for the beginning of expansion of 126,300 (CI: 91,200-164,300) years ago.

\section{Bandicota bengalensis}

We obtained 24 Cytb sequences (1026 bp) for B. bengalensis from the databases, consisting of 23 from Myanmar (Mori et al. 2020) and one from Pakistan. We then constructed an ML tree (Fig. 2c) and MJ network, in which an apparent starlike structure was not seen (Fig. 3c). Mismatch distribution analysis (Supplementary Fig. S1) and neutrality tests were performed on the 23 sequences from Myanmar; the Tajima's $D$ obtained was significantly negative $(P=0.014)$, and Fu's $F$ s was not significant (Table 2 ). The $\tau$ value was calculated to be 0.91 (CI: $0.43-1.52$ ), with an estimated time of expansion initiation, using the evolutionary rate of 0.11 substitutions/ site/myr, of 4000 (CI: 1900-6700) years ago.

\section{Mus musculus}

We obtained four new Cytb sequences (1140 bp) of M. musculus from Taunggyi, Myanmar and combined those with previously determined sequences including three from Manipur, India $(n=$ 19). We constructed an ML tree using these (Fig. 2d) and MJ network (Fig. 3d), revealing that all 15 haplotypes from Myanmar and Manipur belonged to cluster CAS-1, the major lineage found over a large area of Southeast Asia and East Asia, including the Japanese Islands (Suzuki et al. 2013, Kuwayama et al. 2017). We assessed the population dynamics of M. musculus and obtained consistent signals of population expansion in the analyses of mismatch distribution (Supplementary Fig. S1) and neutrality tests (Table 2). The $\tau$ values calculated for two datasets, Myanmar and Manipur $(n=19)$ and Myanmar plus other localities $(n=23)$, were 1.25 (CI: $0.12-1.97)$ and 1.36 (CI: 0.57-2.01), respectively. The initiation dates of the expansion events were calculated as 5000 (CI: 500-7900) and 5400 (CI: 2300-8000) years ago, respectively (Table 2).

\section{Discussion}

We conducted this study to elucidate the evolutionary histories of the Myanmar populations of four species of rodents that live in close proximity to humans- $R$. exulans, $\mathrm{RrC}$, $B$. bengalensis, and M. musculus. By comparing patterns in their genetic structure and population dynamics, we noticed apparent differences among these four species in terms of their levels of genetic diversity and presence or absence of rapid expansion signals. Our data allowed us to reconstruct demographic histories and estimate times at which the expansion events began, although the accuracy of these calculations was limited by relatively small sample sizes. $\mathrm{RrC}$ exhibited relatively high genetic diversity, whereas the remaining three species possessed relatively low levels of genetic diversity (Fig. $3)$. Moreover, signals of rapid expansion events were observed for three species, $\operatorname{RrC}, B$. bengalensis, and M. musculus, whereas no expansion signal was observed for $R$. exulans, using the dataset of haplotypes from Myanmar. Our results allowed us to reconstruct their natural histories and to better understand the factors shaping the diversity of commensal rodents, which are assumed to operate in a speciesspecific manner (Fig. 4), as discussed below.

The Myanmar population of $R$. exulans is characterized by a low level of genetic diversity, no expansion signal, no apparent geographic differentiation in Myanmar, and substantial affinity with the populations of neighboring countries. These results indicate that the population of $R$. exulans emerged relatively recently in Myanmar. Thomson et al. (2014) first revealed the deeper divergence of $R$. exulans populations in ISEA compared to those in MSEA, hypothesizing that this species originated in the Indonesian islands. The network that we created based on the dataset of short sequences ( $381 \mathrm{bp}$, Thomson et al. 2014) exhibited a phylogeographic trend (Fig. 3a) that supports the hypothesis of Thomson et al. (2014), exhibiting a rapid expansion signal, as has been reported previously (Thomson et al. 2014), and an expansion start time of ca. 11,000 years ago (Table 2, Fig. 4). The point in time when R. exulans arrived in Myanmar from other geographic regions such as Indonesia remains unclear. One possibility is that some haplotypes of ISEA origin were introduced quite recently, even in modern times.

For $\mathrm{RrC}$, the mtDNA sequences we obtained from Myanmar were found to belong to $\mathrm{RrC}$ Lineage II, which is assumed to be distributed from Myanmar in the west to the Japanese Islands in the east (Aplin et al. 2011). We disclosed a distinct sublineage, referred to here as IIa-1, comprising haplotypes from Myanmar (this study) and the neighboring region of Manipur, India (Chingangbam et al. 2015). Hence, it has been revealed that the Arakan Mountain system on the border of India and Myanmar may not serve as a geographic barrier for roof rats. The cluster exhibited a star-like structure and possessed significant signals of rapid expansion, with a $\tau$ value of 6.79 (1140 bp; Table 2). Using an evolutionary rate of 0.047 substitutions/site/myr for $C y t b$ sequences (Honda et al. 2019), the expansion time was estimated as 63,000 years BP (CI: 44,000-77,000 years ago), corresponding to the rapid 
Fig. 4 Schematic representation of possible population expansion and dispersal processes inferred from mtDNA sequence variation in the Myanmar populations of Rattus exulans, Rattus rattus complex (RrC), Bandicota bengalensis, and Mus musculus. a The marine oxygen isotope curve for the last 140,000 years is adapted from Petit et al. (1999). b Rapid expansion events inferred from mtDNA analysis are plotted at the corresponding Marine Isotope Stage (MIS) periods: MIS $5 \mathrm{e}(\mathrm{RrC}$ sequences from Myanmar and Manipur, India), early MIS 3 (RrC Lineage IIa-1), and early MIS 1 ( $\mathrm{RrC}$ sequences from Vietnam, China, and Japan; see Aplin et al. 2011). The expansion events suggested by the $C y t b$ sequences of $R$. exulans (Myanmar), B. bengalensis (Myanmar), and M. musculus (Myanmar and Manipur) are indicated. The star-shaped marks indicate rapid expansion events at MIS 5e (red), early MIS 3 (orange), MIS 1 (blue), and mid Holocene (green). c A geographic map showing an ancestral reconstruction of RrC, B. bengalensis, and $M$. musculus eastward dispersals over the last 130,000 years across the Indo-Malayan region (Table 2). In RrC, the expansion event was likely linked to the dispersal event from Myanmar to Bali, Indonesia (Aplin et al. 2011) a
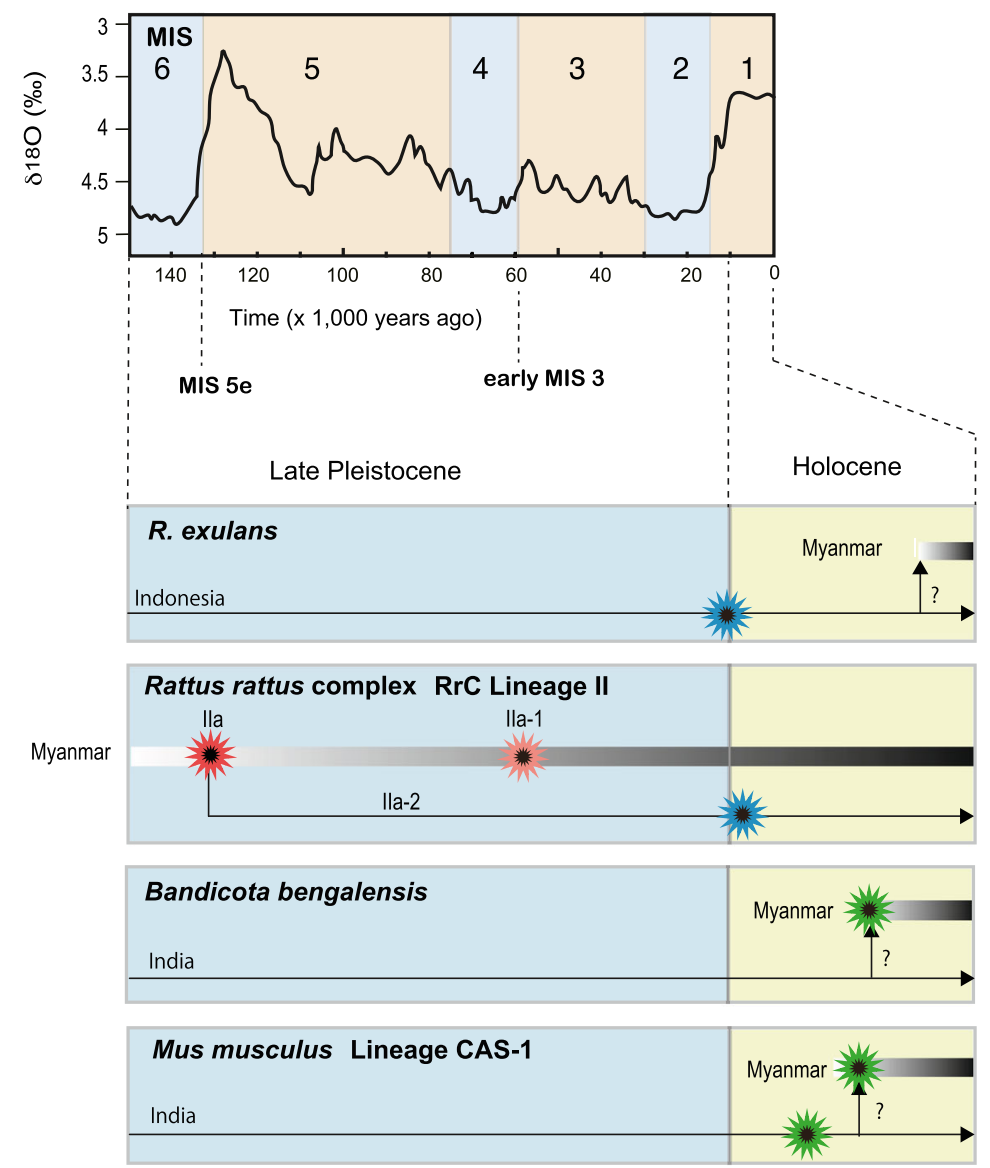

rapid expansion predicted

C
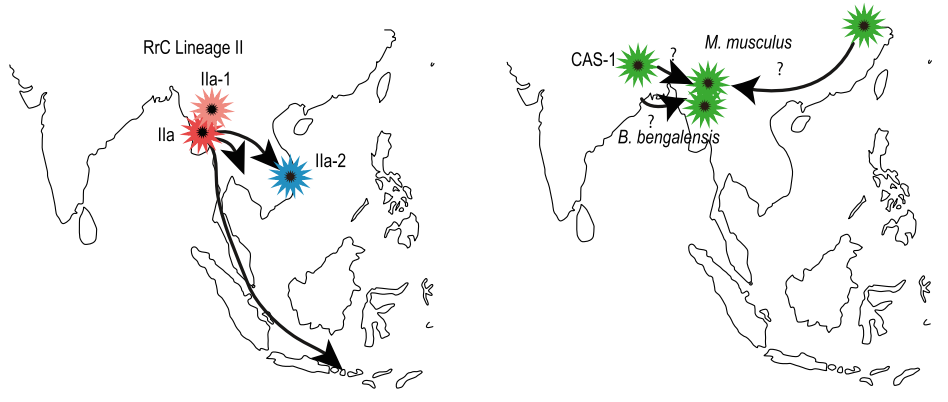

warming period during early MIS 3, following a bottleneck event during the colder period of MIS 4 (e.g., Woltering et al. 2011) (Fig. 4). Notably, the entire set of haplotypes from Myanmar and Manipur exhibited expansion signals (Table 2), with a $\tau$ value of 8.06 and an estimated expansion start time of ca. 140,000 years ago, corresponding to MIS 5e. The cluster of haplotypes IIa (Fig. 2a, "IIA" in Aplin et al. 2011) from the easternmost countries of Eurasia, Vietnam, China, and Japan also exhibited evidence of expansion, with a $\tau$ value of 1.96 (Aplin et al. 2011; Table 2). These results further indicate that $\mathrm{RrC}$ Lineage II experienced a bottleneck and subsequent population expansion at three different time points, including during the influential periods of MIS 5e and early MIS 3 in the region of the Arakan Mountains (Fig. 4). The sudden expansion of IIa-2 in the eastern parts of Eurasia occurred as recently as 9400 years ago, the beginning of Holocene (Table 2), but it remains uncertain whether this was a result of human activities (Aplin et al. 2011) or of global environmental fluctuation.

Similar to R. exulans, B. bengalensis exhibits a low level of genetic diversity, as previously reported (Mori et al. 2020; Fig. 3 , Table 2), although the species is quite common in paddy fields and livestock farms in Myanmar. Analogous to the above mentioned predicted history of $R$. exulans, the 
distribution of $B$. bengalensis may be explained as a recent invasion from another geographic area, namely the Indian subcontinent. This possibility may also explain the apparent geographic partitioning of haplotypes; haplotypes are spatially separated from one another (Mori et al. 2020). Contrary to the case of $R$. exulans, the dataset of $B$. bengalensis haplotypes from Myanmar yielded a rapid expansion signal, with an estimated expansion initiation time of 4000 (CI: 1900-6700) years ago. This implies that a geographic area including Myanmar experienced noteworthy historical events at this time (Fig. 4), and a plausible explanation is the prehistoric development of paddy rice cultivation in the geographic area (Fuller 2011). However, one haplotype from Pyay (Locality 4 in Fig. 1b) was markedly divergent from the other haplotypes, with genetic distance of $0.011-0.012$ (Fig. 2c). This may imply that the species has been distributed in Myanmar for a period of time longer than 100,000 years. Alternatively, it could be the result of a separate introduction from a different location. The small number of samples analyzed and the lack of sequence data from the Indian subcontinent are issues that we plan to address in future research to clarify the evolutionary history of this species.

For M. musculus, all haplotypes from Myanmar belonged to CAS-1, which is known to occupy Pakistan, India, and Southeast and East Asian countries including China (Suzuki et al. 2013; Chingangbam et al. 2015; Bibi et al. 2017; Myat Myat Zaw et al. 2019). In this study, Myanmar haplotypes, together with those of the neighboring area of easternmost India (Manipur), are shown to form a star-like cluster (Table 2, Fig. 3, Supplementary Fig. S1), implying that, for commensal mice, the Arakan Mountain system has no role as a geographic barrier between India and Myanmar. The appearance of a signal of rapid expansion may suggest that a single colonization event from either India or China, both of which are considered centers of diversification of the CAS-1 system (Suzuki et al. 2013; Kuwayama et al. 2017), shaped the genetic diversity of the CAS-1 mice of Myanmar. The expansion event for the CAS-1 sequences from Myanmar and its neighboring area $(n=19)$ was estimated to have occurred 5000 (CI: 5007900 ) years ago (Table 2). These results suggest that human activities during the Holocene were involved in driving the sudden expansion of M. musculus in Myanmar (Fig. 4), as has been predicted previously (Myat Myat Zaw et al. 2019). In our previous study, we showed that the CAS-1 lineage experienced two expansion events (Suzuki et al. 2013; Kuwayama et al. 2017), which occurred 7000-8000 years ago in India and around 4000 years ago in China. Given the suggestion that rice fields emerged in eastern India and Yunnan, China, approximately $4000-4500$ years ago (Fuller 2011), it is plausible that the sudden expansion event in Myanmar was triggered by the spatial expansion of paddy fields.

\section{Conclusion}

We assessed the evolutionary histories of murine species commonly seen in human-occupied areas of Myanmar, by comparing the sequence variations of $C y t b$ in the Pacific rat (R. exulans), roof rat ( $\mathrm{RrC})$, lesser bandicoot rat (B. bengalensis) and house mouse (M. musculus). Cytb sequences of $\mathrm{RrC}, R$. exulans, and M. musculus from Myanmar were determined and used for phylogeographic analysis, along with sequences obtained from databases. In roof rats, the Myanmar $C y t b$ sequences were shown to belong to $\mathrm{RrC}$ Lineage II, which ranges from northeast India to Thailand, Vietnam, China, and Japan. A majority of the haplotypes from Myanmar and the neighboring region of Manipur, India can be integrated into two nested clusters containing signals of rapid population expansion. Employing a time-dependent evolutionary rate, the expansion start times based on nucleotide substitution levels were calculated to be 63,000 (CI: 44,000-77,000) and 140,000 (CI: 101,000$183,000)$ years ago, suggesting that both the colder period and subsequent warmer period during the transition from MIS 4 to MIS 3 and MIS 5e were involved, respectively (Fig. 4). This finding implies that species found in subtropical areas had been affected by late Quaternary environmental fluctuations, as had those in areas of higher latitude (Suzuki et al. 2015; Hanazaki et al. 2017; Honda et al. 2019).

The mtDNA of RrC Lineage II exhibits a higher level of genetic diversity in Myanmar, implying that the area is its point of origin. The genetic diversities of $R$. exulans, M. musculus, and B. bengalensis from Myanmar, in contrast, were relatively low, suggesting that the three species were introduced to Myanmar from neighboring countries relatively recently. The haplotypes of $B$. bengalensis and M. musculus from Myanmar exhibited population expansion signals with an estimated expansion time of 4000-5000 years ago (Fig. 4), probably linked with prehistoric rice field development. By contrast, no expansion signal associated with mid-Holocene human activities was detected for $R$. exulans or $\mathrm{RrC}$ in Myanmar, suggesting that rice field development may not have been significantly associated with the population dynamics of these two rat species. In a future study, we will address the lineage dynamics of these commensal rodents to obtain a comprehensive view of their evolutionary histories at higher resolution using whole mitochondrial genome sequences $(\mathrm{Li}$ et al. 2020).

Acknowledgments We wish to express our gratitude to Pho Kaung, Nyunt Pe, Thet Tun Aung, Nyunt Soe, Maung Thynn, Myinzu Minn, Hla Hla Win, Khin San Wai, and Mie Mie Sein for their encouragement to conduct this research collaboration. Our appreciation and thanks go to Jun J. Sato, Khin Maung Htwe, Khin Maung Than, Mie Mie Kyaw, Myo Myo Aye, Ryo Nakao, Shin-ichiro Kawada, and Satoshi Ohdachi for their active cooperation in collecting mouse samples. We wish to express our appreciation to Kimiyuki Tsuchiya for his valuable comments. 
Furthermore, we wish to acknowledge the two anonymous reviewers for their constructive comments. This study was supported by a grant-in-aid for Scientific Research (B) to HS from the Japanese Society for the Promotion of Sciences (JSPS; 17H04604). This study was conducted in part with the support of a JSPS KAKENHI Grant Numbers (JP18H05508, 24405045) and grants-in aid from the Japan Agency for Medical Research and Development (AMED) (JP15fk0108005, JP16fk0108117, JP17fk0108217, JP18fk0108017, JP19fk0108097, and JP20fk0108097).

Open Access This article is licensed under a Creative Commons Attribution 4.0 International License, which permits use, sharing, adaptation, distribution and reproduction in any medium or format, as long as you give appropriate credit to the original author(s) and the source, provide a link to the Creative Commons licence, and indicate if changes were made. The images or other third party material in this article are included in the article's Creative Commons licence, unless indicated otherwise in a credit line to the material. If material is not included in the article's Creative Commons licence and your intended use is not permitted by statutory regulation or exceeds the permitted use, you will need to obtain permission directly from the copyright holder. To view a copy of this licence, visit http://creativecommons.org/licenses/by/4.0/.

\section{References}

Aplin KP, Brown P R, Jacob J, Krebs C J, Singleton GR (2003) Field Methods for Rodent Studies in Asia and the Indo-Pacific. Australian Centre for International Agricultural Research, Canberra

Aplin KP, Suzuki H, Chinen AA, Chesser RT, Ten Have J, Donnellan SC, Austin J, Frost A, Gonzalez JP, Herbreteau V, Catzeflis F, Soubrier J, Fang YP, Robins J, Matisoo-Smith E, Bastos AD, Maryanto I, Sinaga MH, Denys C, Van Den Bussche RA, Conroy C, Rowe K, Cooper A (2011) Multiple geographic origins of commensalism and complex dispersal history of black rats. PLoS ONE 6:e26357

Auffray JC, Britton-Davidian J (2012) The house mouse and its relatives: systematics and taxonomy. In: Macholán M, Baird SJE, Munclinger P, Piálek J (eds) Evolution of the House Mouse. Cambridge University Press, Cambridge, pp 1-34

Bandelt HJ, Forster P, Röhl A (1999) Median-joining networks for inferring intraspecific phylogenies. Mol Biol Evol 16:37-48

Bibi S, Nadeem MS, Wiewel AS, Beg MA, Hameed K, Jabeen M, Raja GK (2017) Mitochondrial genetic diversity and phylogeography of Mus musculus castaneus in northern Punjab, Pakistan. Zool Sci 34: 490-497

Bintanja R, van de Wal RSW, Oerlemans J (2005) Modelled atmospheric temperatures and global sea levels over the past million years. Nature 437:125-128

Boursot P, Auffray JC, Britton-Davidian J, Bonhomme F (1993) The evolution of house mouse. Annu Rev Ecol Syst 24:119-152

Chingangbam DS, Laishram JM, Suzuki H (2015) Molecular phylogenetic characterization of common murine rodents from Manipur, northeast India. Genes Genet Syst 90:21-30

Chinen AA, Suzuki H, Aplin KP, Tsuchiya K, Suzuki S (2005) Preliminary genetic characterization of two lineages of black rats (Rattus rattus sensu lato) in Japan with evidence for introgression at several localities. Genes Genet Syst 80:367-375

Corbet GB, Hill JE (1992) The Mammals of the Indo-Malayan Region: A Systematic Review. Oxford University Press, Oxford
Conroy CJ, Rowe KC, Rowe KM, Kamath PL, Aplin KP, Hui L, James DK, Moritz C, Patton JL (2013) Cryptic genetic diversity in Rattus of the San Francisco Bay region, California. Biol Invasions 15:741758

Excoffier L, Lischer HE (2010) Arlequin suite ver 3.5: a new series of programs to perform population genetics analyses under Linux and Windows. Mol Ecol Resources 10:564-567

Excoffier L, Schneider S (1999) Why hunter-gatherer populations do not show signs of Pleistocene demographic expansions. Proc Natl Acad Sci USA 96:10597-10602

Fuller DQ (2011) Pathways to Asian civilizations: tracing the origins and spread of rice and rice cultures. Rice 4:78-92

Hanazaki K, Tomozawa M, Suzuki Y, Kinoshita G, Yamamoto M, Irino T, Suzuki H (2017) Estimation of evolutionary rates of mitochondrial DNA in two Japanese wood mouse species based on calibrations with Quaternary environmental changes. Zool Sci 34:201-210

Harpending HC (1994) Signature of ancient population growth in a lowresolution mitochondrial DNA mismatch distribution. Hum Biol 66: 591-600

Ho SYW, Lanfear R, Bromham L, Phillips MJ, Soubrier J, Rodrigo AG, Cooper A (2011) Time dependent rates of molecular evolution. Mol Ecol 20:3087-3101

Honda A, Murakami S, Harada M, Tsuchiya K, Kinoshita G, Suzuki H (2019) Late Pleistocene climate change and population dynamics of Japanese Myodes voles inferred from mitochondrial cytochrome $b$ sequences. J Mammal 100:1156-1168

Irschick DJ, Vitt LJ, Zani PA, Losos JB (1997) A comparison of evolutionary radiations in mainland and Caribbean Anolis lizards. Ecology 78:2191-2203

Jansen E, Overpeck J, Briffa KR, Duplessy J-C, Joos F, MassonDelmotte V, Olago D, Otto-Bliesner B, Peltier WR, Rahmstorf S, Ramesh R, Raynaud D, Rind D, Solomina O, Villalba R, Zhang D (2017) Palaeoclimate. In: Solomon S, Qin D, Manning M, Chen Z, Marquis M, Averyt KB, Tignor M, Miller HL (eds) Climate Change 2007: The Physical Science Basis. Contribution of Working Group I to the Fourth Assessment Report of the Intergovernmental Panel on Climate Change. Cambridge University Press, Cambridge and New York, pp 433-497

Jones EP, Eager HM, Gabriel SI, Jóhannesdóttir F, Searle JB (2013) Genetic tracking of mice and other bioproxies to infer human history. Trends Genet 29:298-308

Kambe Y, Nakata K, Yasuda SP, Suzuki H (2012) Genetic characterization of Okinawan black rats showing coat color polymorphisms of white spotting and melanism. Genes Genet Syst 87:29-38

Kohli BA, Fedorov VB, Waltari E, Cook JA (2015) Phylogeography of a Holarctic rodent (Myodes rutilus): testing high-latitude biogeographical hypotheses and the dynamics of range shifts. J Biogeogr 42:377-389

Kosoy M, Khlyap L, Cosson JF, Morand S (2015) Aboriginal and invasive rats of genus Rattus as hosts of infectious agents. Vector Borne Zoonot Dis 15:3-12

Kumar S, Stecher G, Tamura K (2016) MEGA7: molecular evolutionary genetics analysis version 7.0 for bigger datasets. Mol Biol Evol 33: 1870-1874

Kuwayama T, Nunome M, Kinoshita G, Abe K, Suzuki H (2017) Heterogeneous genetic make-up of Japanese house mice (Mus musculus) created by multiple independent introductions and spatio-temporally diverse hybridization processes. Biol J Linnean Soc 122:661-674

Lambeck K, Esat TM, Potter EK (2002) Links between climate and sea levels for the past three million years. Nature 419:199-206

Leigh JW, Bryant D (2015) POPART:full-feature software for haplotype network construction. Methods Ecol Evol 6:1110-1116

Li Y, Fujiwara K, Osada N, Kawai Y, Takada T, Kryukov AP, Abe K, Yonekawa H, Shiroishi T, Moriwaki K, Saitou N, Suzuki H (2020) House mouse Mus musculus dispersal in East Eurasia inferred from 
98 newly determined complete mitochondrial genome sequences. Heredity. https://doi.org/10.1038/s41437-020-00364-y

Lisiecki LE, Raymo ME (2005) A Pliocene-Pleistocene stack of 57 globally distributed benthic $\delta^{18} \mathrm{O}$ records. Paleoceanography 20: PA1003. https://doi.org/10.1029/2004PA001071

Marshall JT (1988) Family Muridae: rat and mice. In: Lekagul B, McNeely JA (eds) Mammals of Thailand. Association for the Conservation of Wildlife, Sahakranbhat Co., Bangkok, pp 397-487

Matisoo-Smith E, Robins JH (2004) Origins and dispersals of Pacific peoples: evidence from mtDNA phylogenies of the Pacific rat. Proc Natl Acad Sci USA 101:9167-9172

Medway L (1969) The Wild Mammals of Malaya and Off Shore Islands Including Singapore. Oxford University Press, London

Mori S, Thwe T, Thu WM, Yasuda SP, Bawm S, Tsuchiya K, Katakura K, Arai S, Yoshimatsu K, Suzuki H (2020) Species and genetic diversity of Bandicota (Murinae, Rodentia) from Myanmar based on mitochondrial and nuclear gene sequences. Mammal Res 65: 493-502

Musser G, Carleton M (2005) Superfamily Muroidea. In: Wilson DE, Reeder DM (eds) Mammal Species of the World: A Taxonomic and Geographic Reference. Johns Hopkins University, Baltimore, pp 894-1531

Myat Myat Zaw K, Thwe T, Shimada T, Maung Maung Theint S, Saing KM, Bawm S, Katakura K, Suzuki H (2019) Molecular characterization of species of the subgenus Mus from Myanmar. Zool Sci 36: 299-305

Pagès M, Bazin E, Galan M, Chaval Y, Claude J, Herbreteau V, Michaux J, Piry S, Morand S, Cosson JF (2013) Cytonuclear discordance among Southeast Asian black rats (Rattus rattus complex). Mol Ecol 22:1019-1034

Pagès M, Chaval Y, Herbreteau V, Waengsothorn S, Cosson JF, Hugot JP, Morands S, Michaux J (2010) Revisiting the taxonomy of the Rattini tribe: a phylogeny-based delimitation of species boundaries. BMC Evol Biol 10:184

Petit JR, Jouzel J, Raynaud D, Barkov NI, Barnola JM, Basile I, Bender M, Chappellaz J, Davis M, Delaygue G, Delmotte M, Kotlyakov VM, Legrand M, Lipenkov VY, Lorius C, Pepin L, Ritz C, Saltzman E, Stievenard M (1999) Climate and atmospheric history of the past 420,000 years from the Vostok ice core, Antarctica. Nature 399:429-436

Posada D, Buckley T (2004) Model selection and model averaging in phylogenetics: advantages of Akaike information criterion and Bayesian approaches over likelihood ratio tests. Syst Biol 53:793808

Rogers AR (1995) Genetic evidence for a Pleistocene population explosion. Evolution 49:608-615

Rogers AR, Harpending H (1992) Population growth makes waves in the distribution of pairwise genetic differences. Mol Biol Evol 9:552569
Sawagaki T, Aoki T, Hasegawa H, Iwasaki S, Iwata S, Hirakawa K (2004) Late Quaternary glaciations in Japan. In: Ehlers J, Gibbard PL (eds) Quaternary Glaciations-Extent and Chronology, Part III: South America, Asia, Africa, Australasia, Antarctica. Developments in Quaternary Science, Elsevier, Amsterdam, pp 217-225

Shang S, Fan DD, Yin P, Burr G, Zhang MY, Wang Q (2018) Late Quaternary environmental change in Oujiang delta along the northeastern Zhe-Min Uplift zone (Southeast China). Palaeogeogr Palaeoclimatol Palaeoecol 492:64-80

Shimada T, Aplin KP, Jogahara T, Lin LK, Herbreteau V, Gonzalez JP, Suzuki H (2007) Complex phylogeographic structuring in a continental small mammal from East Asia, the rice field mouse, Mus caroli (Rodentia, Muridae). Mammal Study 32:49-62

Shimada T, Aplin KP, Suzuki H (2010) Mus lepidoides (Muridae, Rodentia) of central Burma is a distinct species of potentially great evolutionary and biogeographic significance. Zool Sci 27:449-459

Shimada T, Sato JJ, Aplin KP, Suzuki H (2009) Comparative analysis of evolutionary modes in $\mathrm{Mclr}$ coat color gene in wild mice and mustelids. Genes Genet Syst 84:225-231

Srinivasulu C, Srinivasulu B (2012) South Asian Mammals: Their Diversity, Distribution, and Status. Springer, New York

Suzuki H, Nunome M, Kinoshita G, Aplin KP, Vogel P, Kryukov AP, Jin ML, Han SH, Maryanto I, Tsuchiya K, Ikeda H, Shiroishi T, Yonekawa H, Moriwaki K (2013) Evolutionary and dispersal history of Eurasian house mice Mus musculus clarified by more extensive geographic sampling of mitochondrial DNA. Heredity 111:375-395

Suzuki Y, Tomozawa M, Koizumi Y, Tsuchiya K, Suzuki H (2015) Estimating the molecular evolutionary rates of mitochondrial genes referring to Quaternary ice age events with inferred population expansions and dispersals in Japanese Apodemus. BMC Evol Biol 15: 187. https://doi.org/10.1186/s12862-015-0463-5

Thomson V, Aplin KP, Cooper A, Hisheh S, Suzuki H, Maryanto I, Yap G, Donnellan SC (2014) Molecular genetic evidence for the place of origin of the Pacific rat, Rattus exulans. PLoS ONE 9:e91356

Thomson V, Wiewel A, Chinen A, Maryanto I, Sinaga MH, How R, Aplin K, Suzuki H (2018) A perspective for resolving the systematics of Rattus, the vertebrates with the most influence on human welfare. Zootaxa 4459:431-452

Tollenaere C, Brouat C, Duplantier JM, Rahalison L, Rahelinirina S, Pascal M, Mone H, Mouahid G, Leirs H, Cosson JF (2010) Phylogeography of the introduced species Rattus rattus in the western Indian Ocean, with special emphasis on the colonization history of Madagascar. J Biogeogr 37:398-410

Wilson DE, Lacher TE, Mittermeier RA (2016) Handbook of the Mammals of the World, Vol. 6, Lagomorphs and Rodents I. Lynx Edicions, Barcelona

Woltering M, Johnson TC, Werne J, Schouten S, Sinninghe Damste JS (2011) Late Pleistocene temperature history of southeast Africa: a TEX $_{86}$ temperature record from Lake Malawi. Palaeogeogr Palaeoclimatol Palaeoecol 303:93-102 